\title{
Project Number: 1024833 \\ Aqueous Complexation Reactions Governing the Rate and Extent of Biogeochemical U(VI) Reduction ERKP464
}

Oak Ridge National Laboratory: Scott C. Brooks*, Wenming Dong, Sue Carroll (*Oak Ridge National Laboratory, Environmental Sciences Division, P.O. Box 2008, MS 6038, Oak Ridge, TN 37931-6038, brookssc@ornl.gov; (865) 574-6398)

Pacific Northwest National Laboratory: James K. Fredrickson. Argonne National Laboratory: Kenneth M. Kemner and Shelly D. Kelly

Research Objective: The proposed research will elucidate the principal biogeochemical reactions that govern the concentration, chemical speciation, and reactivity of the redox-sensitive contaminant uranium. The results will provide an improved understanding and predictive capability of the mechanisms that govern the biogeochemical reduction of uranium in subsurface environments. In addition, the work plan is designed to:

- Generate fundamental scientific understanding on the relationship between U(VI) chemical speciation and its susceptibility to biogeochemical reduction reactions.

- Elucidate the controls on the rate and extent of contaminant reactivity.

- Provide new insights into the aqueous and solid speciation of $\mathrm{U}(\mathrm{VI}) / \mathrm{U}(\mathrm{IV})$ under representative groundwater conditions.

These goals and objectives will be met through a series of hypothesis-driven tasks that focus on (i) the use of well-characterized mineral isolates and natural subsurface mineral assemblages, (ii) advanced spectroscopic techniques to monitor changes in the aqueous and solid-phase speciation of uranium, and (iii) close collaboration between microbiologists, geochemists, and physicists to provide for rigorous design and interpretation of experiments.

Research Progress and Implications: This report summarizes work after two years of a three year project.

Mission Relevance. The experimental and numerical results of this research will quantify the conditions that govern the rate and extent of U(VI) reduction under representative subsurface conditions. By providing an improved understanding of the competitive processes that affect contaminant reactivity in multicomponent systems, we will enhance the successful application of microbially mediated contaminant stabilization in the field. The enhanced understanding derived from this research will allow for the development of innovative approaches for in situ bioimmobilization of radionuclides at DOE contaminated sites and a better understanding of the requirements for maintaining contaminants as reduced and poorly soluble phases.

Uranium(VI) Analysis and Quantification: Kinetic phosphorimetry analysis (KPA) is used to quantify $\mathrm{U}(\mathrm{VI})$ and, following sample oxidation, total $\mathrm{U}$. The difference between total $\mathrm{U}$ and $\mathrm{U}(\mathrm{VI})$ provides concentration of U(IV) in samples. Using procedures outlined in Oppenheimer et al. (1983) and adopting Type I and Type II error rates of 5\%, the following practical analytical limits for our laboratory are (definitions from (OPPENHEIMER et al., 1983) and (GIBBONS and COLEMAN, 2001)):

Critical level $=\mathbf{7 . 5} \times \mathbf{1 0}^{-11} \mathrm{M}$ ("lowest measured concentration above which one can confidently assert that the measured analyte has been detected").

Limit of detection $=\mathbf{1 . 5} \times \mathbf{1 0}^{-10} \mathbf{M}$ ("lowest measured concentration above which the analyte can be distinguished from the noise”). 
Determination limit $=\mathbf{3 . 6} \times \mathbf{1 0}^{-10} \mathbf{M}$ ("level at which measurement precision will be satisfactory for quantitative determination”).

Systematic evaluation of proposed solution chemistries identified some quenching agents that interfere with U(VI) quantification by KPA. Potential remedies for these interferences have also been tested and identified. The alkaline earth elements $\mathrm{Mg}$, $\mathrm{Ca}$, and $\mathrm{Sr}$ and the transition metal Fe all exhibit significant quenching at concentrations above $10^{-3} \mathrm{M}$. For the range of experimental conditions we anticipate using, this interference can be removed through sample dilution and we will still retain the excellent sensitivity provided by KPA. Similarly, chloride concentrations above $10^{-3} \mathrm{M}$ create severe quenching. Because we must avoid the use of nitrate salts in some experiments due to its use by bacteria as a competing electron acceptor, chloride concentrations may be quite high in some experiments. Therefore, simple dilution may be insufficient to resolve the problem. A wet ashing procedure was developed that successfully eliminates the chloride interference at concentrations as high as $0.1 \mathrm{M}$ (highest concentration tested).

The experimental plan also includes the use of EDTA to regulate the solution activity of metals. Uranium measurements are much more sensitive to the presence of EDTA with concentrations of this compound exceeding $10^{-5} \mathrm{M}$ causing significant positive interference whereas at EDTA concentrations above $10^{-4} \mathrm{M}$ $\mathrm{U}$ measurement efficiency fell to $0 \%$. The magnitude of the effect was inversely related to the concentration of U(VI): EDTA had greater effect at lower U concentration. In this case dilution alone would not solve the problem as U concentrations would be diluted below a reliable level of quantification. The wet ash procedure that was used for chloride proved to be marginally successful: while the quenching was alleviated, $U$ measurement efficiency was still well below an acceptable level. Repeated wet ashing treatments (up to 4 times) could not resolve the problem suggesting that some portion of the EDTA or its breakdown products could not be removed from the samples by our method. However, a combination of multiple wet ashing and a higher sample dilution yielded excellent results. Even with the higher dilution factor we retain the ability to easily observe at least a $99 \%$ loss of U(VI) from solution.

Formation of alkaline earth metal-uranium-carbonate ternary complexes. Ternary complexes of U(VI), $\mathrm{CO}_{3}{ }^{2-}$, and alkaline earth metals $\left(\mathrm{Mg}^{2+}, \mathrm{Ca}^{2+}, \mathrm{Sr}^{2+}, \mathrm{Ba}^{2+}\right)$ may play an important role in the environmental chemistry of uranium. Despite previous efforts to quantify the formation constants for the $\mathrm{Ca}-\mathrm{U}(\mathrm{VI})-\mathrm{CO}_{3}$ complexes, concerns remain and they are not officially recognized in the most recent compilation of $U$ thermodynamic data. We measured the formation constants of ternary complexes $\left(\mathrm{MUO}_{2}\left(\mathrm{CO}_{3}\right)_{3}{ }^{2-}\right.$ and $\left.\mathrm{M}_{2} \mathrm{UO}_{2}\left(\mathrm{CO}_{3}\right)_{3}{ }^{0}\right)$ of uranyl and carbonate with alkaline earth metals $\left(\mathrm{M}^{2+}\right.$ denotes $\mathrm{Mg}^{2+}, \mathrm{Ca}^{2+}, \mathrm{Sr}^{2+}$, and $\mathrm{Ba}^{2+}$ ) with an anion exchange method by varying the metal concentrations $(0.1-5 \mathrm{mmol} / \mathrm{L})$ at $\mathrm{pH} 8.1$ and a constant ionic strength $\left(0.1 \mathrm{~mol} / \mathrm{L} \mathrm{NaNO}_{3}\right)$ under equilibrium with atmospheric $\mathrm{CO}_{2}$. The results indicate that the complexes of $\mathrm{MUO}_{2}\left(\mathrm{CO}_{3}\right)_{3}{ }^{2-}$ and $\mathrm{M}_{2} \mathrm{UO}_{2}\left(\mathrm{CO}_{3}\right)_{3}$ are simultaneously formed for $\mathrm{Ca}^{2+}$ and $\mathrm{Ba}^{2+}$, while $\mathrm{Mg}^{2+}$ and $\mathrm{Sr}^{2+}$ form only the $\mathrm{MUO}_{2}\left(\mathrm{CO}_{3}\right)_{3}{ }^{2-}$ complex under our experimental conditions. The cumulative stability constants for the $\mathrm{MUO}_{2}\left(\mathrm{CO}_{3}\right)_{3}{ }^{2-}$ complex obtained at $\mathrm{I}=0$ are: $\log \beta_{113}=26.11 \pm 0.04$, $27.18 \pm 0.06,26.86 \pm 0.04$, and $26.68 \pm 0.04$ for $\mathrm{Mg}^{2+}, \mathrm{Ca}^{2+}, \mathrm{Sr}^{2+}$ and $\mathrm{Ba}^{2+}$, respectively. For $\mathrm{M}_{2} \mathrm{UO}_{2}\left(\mathrm{CO}_{3}\right)_{3}{ }^{0}$ the value of $\log \beta_{213}$ at $\mathrm{I}=0$ was measured to be $30.70 \pm 0.05$ and $29.75 \pm 0.07$ for $\mathrm{Ca}^{2+}$ and $\mathrm{Ba}^{2+}$, respectively. Based on the formation constants obtained in this study, speciation calculations indicate that at low $\mathrm{Ca}^{2+}$ concentration (e.g., $<2.2 \mathrm{mmol} / \mathrm{L}$ ) $\mathrm{CaUO}_{2}\left(\mathrm{CO}_{3}\right)_{3}{ }^{2-}$ is more important than $\mathrm{Ca}_{2} \mathrm{UO}_{2}\left(\mathrm{CO}_{3}\right)_{3}{ }^{0}$ and that the $\mathrm{Ca}_{2} \mathrm{UO}_{2}\left(\mathrm{CO}_{3}\right)_{3}{ }^{0}$ distribution increased with increasing $\mathrm{Ca}^{2+}$ concentration. Uranium sorption onto anion exchange resins is inhibited by the formation of the neutral $\mathrm{Ca}_{2} \mathrm{UO}_{2}\left(\mathrm{CO}_{3}\right)_{3}{ }^{0}$ species. This information is immediately usable by the Department of Energy in ongoing investigations of the environmental fate and transport of uranium.

Influence of EDTA and pH on Bioreduction of Uranium(VI) in the Presence of Calcium Ions. Previously, we reported that the aqueous $\mathrm{Ca}_{2} \mathrm{UO}_{2}\left(\mathrm{CO}_{3}\right)_{3}{ }^{0}$ complex can effectively inhibit $\mathrm{U}(\mathrm{VI})$ bioreduction (BROOKS et al., 2003). In this study, the bioreduction of U(VI) was investigated in the presence of 2.5 $\mathrm{mM}$ Ca and varying EDTA concentration (1.75-2.5 mM) and $\mathrm{pH}(6.5$ and 7.1) under anoxic conditions. 
The rate and extent of U(VI) bioreduction increased with increasing EDTA concentration (Figure 1). These observations are consistent with decreased $\mathrm{Ca}_{2} \mathrm{UO}_{2}\left(\mathrm{CO}_{3}\right)_{3}{ }^{0}$ concentration due to the competitive

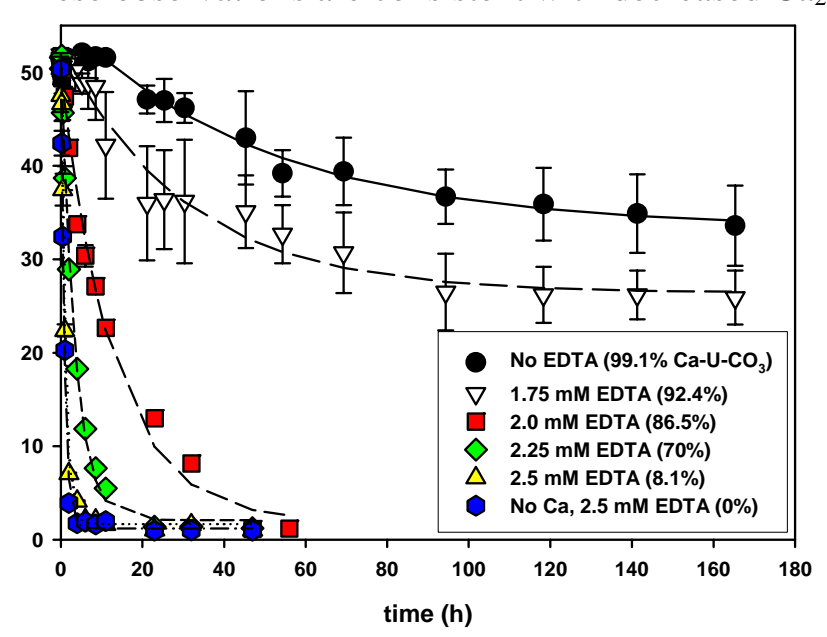

Figure 1 Microbial U(VI) reduction at $\mathrm{pH} 6.5$ as a function of EDTA concentration. As the concentration of EDTA in solution is increased, the fraction of U(VI) in the $\mathrm{Ca}-\mathrm{U}(\mathrm{VI})-\mathrm{CO}_{3}$ complexes decreases and the rate and extent of $\mathrm{U}(\mathrm{VI})$ reduction increases. complexation of $\mathrm{Ca}^{2+}$ by EDTA. The reduced $\mathrm{U}(\mathrm{IV})$ was observed in the forms of uraninite and $\mathrm{U}(\mathrm{IV})$-EDTA complexes in the absence and presence of EDTA, respectively. Faster U(VI) reduction with increased $\mathrm{pH}$ is consistent with a lower predicted $\mathrm{Ca}_{2} \mathrm{UO}_{2}\left(\mathrm{CO}_{3}\right)_{3}{ }^{0}$ concentration at $\mathrm{pH}$ 7.1. U(VI) speciation calculation and EXAFS analysis were applied to confirm our hypothesis that aqueous complexation controlled U(VI) bioreduction through the reactions of $\mathrm{Ca}^{2+}$ with $\mathrm{UO}_{2}\left(\mathrm{CO}_{3}\right)_{3}{ }^{4-}$ and EDTA. In addition, $\mathrm{x}$-ray absorption spectroscopy confirmed the formation of U(IV)-EDTA solution complexes.

Effects of $\mathrm{pH}$, EDTA, and $\mathrm{Ca}^{2+}$ on U(IV) oxidation: A method to determine U(IV) from the total uranium and U(VI) in solutions by laserinduced kinetic phosphorimetry. The effects of $\mathrm{pH}$, EDTA and $\mathrm{Ca}^{2+}$ on the oxidation of biogenic uraninite and U(IV)-EDTA complexes were investigated at acidic and weakly alkaline $\mathrm{pH}$ under atmospheric conditions. The uraninite and U(IV)EDTA were prepared by the bioreduction of U(VI) in the absence and presence of EDTA and $\mathrm{Ca}^{2+}$ under anaerobic conditions. The results indicate that the oxidation rate of uraninite and U(IV)-EDTA increased with increasing $\mathrm{pH}$ and can be well-described with a first-order reaction. In particular, EDTA decreased the oxidation rate at $\mathrm{pH} 1$ and enhanced the oxidation rate at $\mathrm{pH}$ 8.1. At $0.1 \mathrm{M} \mathrm{HNO}_{3}$ medium, the oxidation rate decreased with increasing EDTA concentration, indicating that a treatment of mixed $\mathrm{U}(\mathrm{VI}) / \mathrm{U}(\mathrm{IV})$ samples with the $0.1 \mathrm{M} \mathrm{HNO}_{3}$ and addition of appropriate EDTA can effectively inhibit the oxidation of U(IV), suggesting an improved method to determine U(IV) from the difference of U(VI) and total U in KPA.

$\underline{\text { X-ray absorption spectroscopy identifies calcium-uranyl-carbonate complexes at environmental }}$ concentrations. Current research on bioremediation of uranium-contaminated groundwater focuses on supplying indigenous metal-reducing bacteria with the appropriate metabolic requirements to induce microbiological reduction of soluble uranium(VI) to poorly soluble uranium(IV). Recent studies of uranium(VI) bioreduction in the presence of environmentally relevant levels of calcium revealed limited and slowed uranium(VI) reduction and the formation of a $\mathrm{Ca}-\mathrm{UO}_{2}-\mathrm{CO}_{3}$ complex. However, the stoichiometry of the complex is poorly defined and may be complicated by the presence of a $\mathrm{Na}-\mathrm{UO}_{2}-$ $\mathrm{CO}_{3}$ complex. Such a complex might exist even at high calcium concentrations, as some $\mathrm{UO}_{2}-\mathrm{CO}_{3}$ complexes will still be present. The number of calcium and/or sodium atoms coordinated to a uranyl carbonate complex will determine the net charge of the complex. Such a change in aqueous speciation of uranium(VI) in calcareous groundwater may affect the fate and transport properties of uranium. We performed X-ray absorption fine structure (XAFS) measurements of a series of solutions containing 50 $\mu \mathrm{M}$ uranium(VI) and $30 \mathrm{mM}$ sodium bicarbonate, with various calcium concentrations of $0-5 \mathrm{mM}$. Use of the data series reduced the uncertainty in the number of calcium atoms bound to the $\mathrm{UO}_{2}-\mathrm{CO}_{3}$ complex to approximately 0.6 and enabled spectroscopic identification of the $\mathrm{Na}-\mathrm{UO}_{2}-\mathrm{CO}_{3}$ complex. At nearly neutral $\mathrm{pH}$ values, the numbers of sodium and calcium atoms bound to the uranyl triscarbonate species are found to depend on the calcium concentration, as predicted by speciation calculations. 
Oxidation of $\sim 250 \mu \mathrm{M}, 24 \mathrm{H}$ MR-1, $\mathrm{H}_{2}$ or lactate bioreduced U vs fumarate or pasteurized MR-1 + washed biogenic uraninite $\left(\mathrm{UO}_{2}\right)$ in $30 \mathrm{mM} \mathrm{HCO}_{3}$

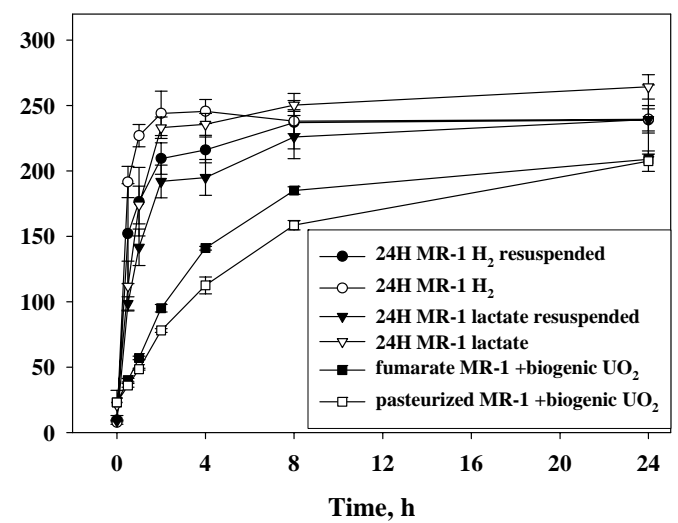

Figure 2 Oxidation of $\mathrm{U}(\mathrm{IV}) \mathrm{O}_{2}$ as a function of antecedent cell culture conditions.

U(IV) oxidation in the presence of Shewanella putrefaciens MR-1. Work at PNNL has focused on quantifying U(IV) oxidation as a function of solution chemistry, source of U(IV), and cell culture conditions. One example of experimental results is provided. Uranium(VI) was reduced by MR-1 using either $\mathrm{H}_{2}$ or lactate as the electron donor. Maintaining anaerobic conditions, cells and associated U(IV) precipitates $\left(\mathrm{UO}_{2}\right)$ were washed via centrifugation and subsequently resuspended in bicarbonate buffer under an air: $\mathrm{CO}_{2}$ headspace. A parallel culture of MR-1 was grown on fumarate in the absence of $\mathrm{U}(\mathrm{VI})$, washed and resuspended as described above; one treatment included pasteurization to prevent further metabolic activity. Exogenous bioreduced $\mathrm{UO}_{2}$ was added to the resuspended fumarate-grown cells. Oxidative release of U(VI) was monitored over time (Figure 2). The most rapid rates occurred in tubes simply exposed to the air. Intermediate rates were observed for biogenic $\mathrm{UO}_{2}$ produced by MR-1 using either $\mathrm{H}_{2}$ or lactate (indigenous $\mathrm{UO}_{2}$ ) and the slowest rates occurred for in the exogenously added $\mathrm{UO}_{2}$ in the presence of the fumarate grown cells. Continued studies are investigating the role of bacterial exopolysaccharides (EPS) and outer membrane cytochromes in U(IV) oxidation.

\section{Research highlights to date}

- Solution chemistry exerts a strong influence on the rate and extent of microbial uranium reduction. Aqueous speciation of U(VI), biogenic U(IV), and other solution components (e.g., Ca) govern contaminant reactivity in multicomponent systems.

- Quantified the formation constants for alkaline earth-uranyl-carbonate complexes. Provided refined values for the $\mathrm{Ca}-\mathrm{U}-\mathrm{CO}_{3}$ complexes. Published the first peer-reviewed and publicly released values for Mg-, Sr-, and Ba- complexes.

- Applied x-ray absorption spectroscopy and novel data analysis techniques to give improved precision for the stoichiometry of the $\mathrm{Ca}-\mathrm{UO}_{2}-\mathrm{CO}_{3}$ complex.

- First report of spectroscopic identification of a Na- $\mathrm{UO}_{2}-\mathrm{CO}_{3}$ complex.

- Stability of biogenic U(IV) governed by antecedent culture conditions.

\section{Planned Activities for final year of project:}

- Quantify individual and synergistic effects of solution chemistry on bacterial U(VI) reduction. For example, testing the presence of calcium or magnesium alone versus the presence of both alkaline earth elements.

- Refined estimate of stability constants for alkaline earth-uranyl-carbonate complexes. Previous research produced equivocal results for some systems. New studies have been designed to reduce these uncertainties.

- Quantify effect of alkaline earth elements on abiotic U(VI) reduction processes (e.g., reduction by $\left.\mathrm{AH}_{2} \mathrm{DS}, \mathrm{Fe}(\mathrm{II})\right)$.

- Determine the ability of synchrotron x-ray techniques to discriminate between inorganic and organic carbon bound to uranyl.

- Use x-ray absorption spectroscopy to characterize the valence state and local chemical environment of $\mathrm{U}$ sorbed to bacterial cell walls in the presence and absence of Ca. 
- Collect higher quality U XAFS data of U(IV)-EDTA moiety in solution to better refine the stereochemical interaction between U(IV) and EDTA.

- Determine the effect of Ca on the rate of oxidation of biogenic uraninite in the presence and absence of bacterial cells.

- Investigate the effect of cellular location (i.e., periplasm versus association with EPS) on the rate of biogenic uraninite oxidation.

\section{Information Access:}

Publications

Kelly, S. D., K. M. Kemner, and S. C. Brooks. in press. X-ray absorption spectroscopy identifies calcium-uranyl-carbonate complexes at environmental concentrations. Geochim. Cosmochim. Acta. doi:10.1016/j.gca.2006.10.013

Dong, W. and S. C. Brooks. 2006. Determination of the formation constants of ternary complexes of uranyl and carbonate with alkaline earth metals $\left(\mathrm{Mg}^{2+}, \mathrm{Ca}^{2+}, \mathrm{Sr}^{2+}\right.$, and $\left.\mathrm{Ba}^{2+}\right)$ using anion exchange method. Environ. Sci. Technol. 40(15):4689-4695. doi: 10.1021/es0606327

Kelly, S. D., K. M. Kemner, S. C. Brooks, J. K. Fredrickson, S. L. Carroll, D. W. Kennedy, J. M. Zachara, A. E. Plymale, and S. Fendorf. 2005. Ca- $\mathrm{UO}_{2}-\mathrm{CO}_{3}$ complexation- Implications for bioremediation of U(VI). Physica Scripta T115:915-917, 2005

Presentations and Published Abstracts

Brooks, S.C., W. Dong, S. L. Carroll, S. D. Kelly, and K. Kemner. 2006. Influence of EDTA and pH on uranium(VI) bioreduction in the presence of calcium ions. Abstracts of the $231^{\text {st }}$ National Meeting, American Chemical Society, Atlanta, GA, 26-30 March 2006.

Dong, W., S. C. Brooks, S. D. Kelly, K. Kemner, and K. A. Orlandini. 2006. Determination of the formation constants of ternary complexes of uranyl and carbonate with alkaline earth metals $\left(\mathrm{Mg}^{2+}\right.$, $\mathrm{Ca}^{2+}, \mathrm{Sr}^{2+}$, and $\mathrm{Ba}^{2+}$ ) by using anion exchange method. Abstracts of the $231^{\text {st }}$ National Meeting, American Chemical Society, Atlanta, GA, 26-30 March 2006.

Dong, W. and S. C. Brooks. 2006. Effects of $\mathrm{pH}$, EDTA, and $\mathrm{Ca}^{2+}$ on oxidation rate of biogenic uraninite and U(IV)-EDTA complexes. Abstracts of the $231^{\text {st }}$ National Meeting, American Chemical Society, Atlanta, GA, 26-30 March 2006.

Brooks, S. C., W. Dong, J. K. Fredrickson, K. M. Kemner, and Shelly D. Kelly. 2005. The Effect of Uranyl-Alkaline Earth Complexes on Bacterial U(VI) Reduction. 2005 International Chemical Congress of Pacific Basin Societies (PACIFICHEM 2005). 15-20 Dec. 2005, Honolulu, Hawaii. INVITED.

Ravel, B., S. D. Kelly, D. Gorman-Lewis, M. I. Boyanov, J. B. Fein and K. M. Kemner. 2006. A pHdependent X-ray absorption spectroscopy study of U adsorption to bacterial cell walls. $13^{\text {th }}$ International XAFS Conference, Stanford University, Palo Alto, CA, July 9-14, 2006.

\section{Literature Cited}

Brooks S. C., Fredrickson J. K., Carroll S. L., Kennedy D. W., Zachara J. M., Plymale A. E., Kelly S. D., Kemner K. M., and Fendorf S. (2003) Inhibition of bacterial U(VI) reduction by calcium. Environ. Sci. Technol. 37(9), 1850-1858.

Gibbons R. D. and Coleman D. E. (2001) Statistical Methods for Detection and Quantification of Environmental Contamination. John Wiley and Sons.

Oppenheimer L., Capizzi T. P., Weppelman R. M., and Mehta H. (1983) Determination of the lowest limit of reliable assay measurement. Anal. Chem 55(4), 638-643. 